\title{
Does Pulmonary Endarterectomy have Arrhythmia Prevention Effect?
}

\author{
Tarik Kivrak, Bedrettin Yıldızeli', Bülent Mutlu² \\ Department of Cardiology, Firat University Hospital, Elazig, ${ }^{1}$ Departments of Thoracic Surgery, ${ }^{2}$ Cardiology, Marmara University Hospital, Istanbul, Turkey
}

\section{Abstract}

Background: The aim of the present study was therefore to evaluate the evolution of electrocardiography (ECG) markers indicator of morbidity and mortality after pulmonary endarterectomy (PEA). It may be a good predictor of mortality and morbidity in chronic thromboembolic pulmonary hypertension (CTEPH) with patients who underwent PEA. PEA may be reduced risk of arrhythmia in patients with CTEPH. However, this claim must to be supported with long-term results. Materials and Methods: We collected demographic, ECG, and echocardiographic parameters data (baseline and after the operation) in patients undergoing PEA for CTEPH at our institution from 2009 to 2013 . We assessed 62 CTEPH patients who underwent PEA. Results: P wave amplitude in DII, PR interval, $P$ and QT dispersion changed significantly at 3 months after surgery. The $\mathrm{P}$ dispersion $(17.66 \pm 6.2, P<0.04)$ and QT dispersion $(23.75 \pm 11.37, P<0.015)$ were longer in before operation than in after operation. Conclusions: In our study, we found in ECG analyses of CTEPH with patients who are undergoing PEA that $P$ dispersion, QT dispersion were changed when compared with before operation. For this reason, we think that PEA reduces the risk of atrial fibrillation and malignant arrhythmia.

Keywords: P wave dispersion, pulmonary endarterectomy, QT dispersion

\section{INTRODUCTION}

Several studies have evaluated the association between RV structure and ECG alterations in patients with either chronic thromboembolic pulmonary hypertension (CTEPH) or pulmonary arterial hypertension (PAH), which could be useful for diagnostic or prognostic purposes. ${ }^{[1-6]}$ However, it is still unknown to what extent the different ECG criteria reflect the changes in mass and volume of the right ventricle, and they are related to the RV overload determined by the elevated pressures in the pulmonary circulation. Unlike other types of pulmonary hypertension, CTEPH can be successfully treated with surgery. It is well demonstrated that pulmonary endarterectomy (PEA) allows dramatic improvements in the right heart hemodynamic profile immediately after surgery. ${ }^{[7,8]}$ On the contrary, regression of hypertrophy and restoration of regular RV systolic function requires more time and take place mainly during the first postoperative year. ${ }^{[9,10]}$ The QT interval reflects electrocardiographic (ECG) parameter of the duration of ventricular repolarization. The QT dispersion is the interleaved variability of QT interval on ECG that reflects regional differences in myocardial repolarization.

\begin{tabular}{|l|l|}
\hline \multicolumn{3}{c|}{ Access this article online } \\
\hline Quick Response Code: & Website: \\
& \\
http://www.ijcva.com
\end{tabular}

Enhanced the QT dispersion has been linked to the occurrence of malignant ventricular arrhythmias and sudden cardiac death. ${ }^{[1-13]} \mathrm{P}$ wave terminal force in lead V1 was found to be an independent predictor of stroke in a vital trial. ${ }^{[14]}$ The aim of the present study was for this reason to evaluate the evolution of ECG parameters as potential predictors of future arrhythmias after PEA. However, this claim must to be supported with long-term results.

\section{Materials and Methods}

The present study is a retrospective evaluation of $62 \mathrm{CTEPH}$ patients who underwent PEA between 2009 and 2013 in the Marmara University Hospital by thoracic surgery and were followed up for at 6 months after surgery. Thoracic surgeon evaluated patients. Patients with Stage 4 did not perform a surgical operation. Exclusion criteria were previous

Address for correspondence: Dr. Tarik Kivrak, Department of Cardiology, Firat University Hospital, Elazig, Turkey. E-mail: tarikkivrak@gmail.com

This is an open access journal, and articles are distributed under the terms of the Creative Commons Attribution-NonCommercial-ShareAlike 4.0 License, which allows others to remix, tweak, and build upon the work non-commercially, as long as appropriate credit is given and the new creations are licensed under the identical terms.

For reprints contact: reprints@medknow.com

How to cite this article: Kivrak T, Yıldizeli B, Mutlu B. Does pulmonary endarterectomy have arrhythmia prevention effect?. Int J Cardiovasc Acad 2018;4:23-7. 
myocardial infarction, significant left valvular heart disease, congenital heart disease, the necessity of additional cardiac surgery, persistent atrial fibrillation/flutter (three patients), and significant chronic lung disease. All patients underwent echocardiographic examination and a 12-lead ECG recording before surgery, at 6 months after surgery as part of the routine PEA follow-up protocol at our center. Conventional 12-lead ECG was recorded with the patient in supine position with commercially available ECG at a paper speed of $25 \mathrm{~mm} / \mathrm{s}$, the sensitivity of $1 \mathrm{mV}=10 \mathrm{~mm}$, a sampling frequency of $500 \mathrm{~Hz}$. Every ECG recorded and analyzed was checked by two expert cardiologists and were used to assess intra- and interobserver variability. The ECG parameters were measured: Heart rate, PR interval, QRS width, $\mathrm{P}$ width, and $\mathrm{P}$ wave amplitude in DII, P wave amplitude in aVL, P wave amplitude in V5, QT duration in DII, QT duration in aVL, QT duration in V5, $\mathrm{P}$ dispersion, and QT dispersion. The $\mathrm{P}$ wave onset and end-points were considered as the intersection of the $P$ wave by the isoelectric line and the junction of the end-point of the $\mathrm{P}$ wave with the isoelectric line, respectively. The maximum $\mathrm{P}$ wave duration was suggested as the most extended $\mathrm{P}$ wave and the longest atrial conduction time, and the variation between the longest and the shortest $\mathrm{P}$ waves were indicated as the $\mathrm{P}$ wave dispersion [Figure 1]. The interval between the points of the isoelectric TP segment intercepted by the onset of the QRS complex and the descending branch of the T wave was suggested as the QT interval and was respective calculated for each derivation. The QT dispersion was determined as the variation between the longest and shortest QT intervals in any origin in the standard 12-lead ECG [Figure 2].

Ultrasound examinations were performed using commercially available echocardiographic equipment (Vivid 7 System). The following parameters were measured to study the right and left ventricle: Left ventricle ejection fraction, right ventricle tissue Doppler value (S'), myocardial perfusion index, pulmonary systolic pressure, right atrium and ventricle diameters, tricuspid annular plane systolic excursion, and degree of tricuspid regurgitation. For statistical analysis, SPSS 16.0 statistical package for Windows (SPSS Inc., Chicago, IL, USA). software was used. Categorical variables were defined as a percentage.

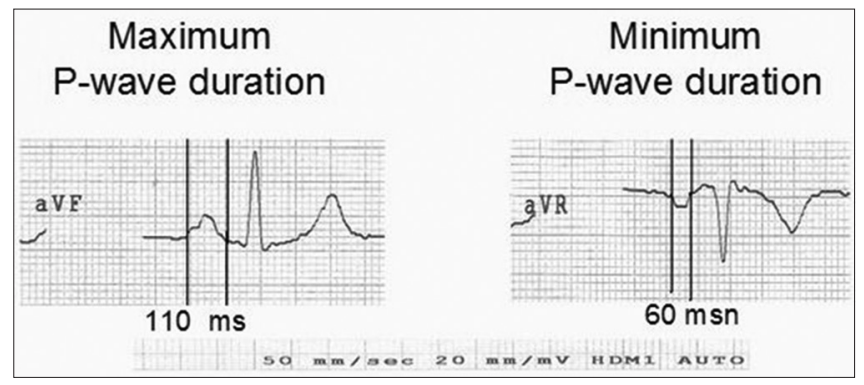

Figure 1: Two complexes extracted from 12-lead surface electrocardiography of a patient. In this case, maximum P-wave duration was observed from lead aVF and the minimum P-wave duration from lead automatic voltage regulator. Pine wilt disease was defined as the difference between the maximum and minimum P-wave durations
Quantitative variables were expressed as a mean \pm standard deviation and for the comparison of variables between two paired groups "paired sample Student T" (parametric distributed parameters) and "Wilcoxon" (for the parameters showing the nonparametric distribution) tests were used. Correlation analyses were performed by Spearman correlation test. $P<0.05$ was accepted statistically significant.

\section{RESULTS}

The patient's clinical characteristic are shown in Table 1. A total of 39 of the patients were of the male gender; mean age was 57 years, the vast majority had severe symptoms, 45 of the patients had a history of deep vein thrombosis, few of them had associated diseases such as chronic obstructive pulmonary disease, diabetes mellitus, and systemic hypertension. Eighty-nine percent of patients had functional Class III-IV. Hemodynamic values are shown in Table 2: the mean pulmonary arterial pressure of patients was $48.7 \pm 14$.9. We assessed 62 CTEPH patients who underwent PEA. P wave amplitude (118.66 \pm 2.77 vs. $109.16 \pm 33.24 . P<0.016)$ India, PR interval $(157.9 \pm 31.51$ vs. $139.35 \pm 29.28, P<0.006)$ $\mathrm{P}$ and QT dispersion changed significantly at 6 months after surgery. The $\mathrm{P}$ dispersion $(27.93 \pm 14.17$ vs. $21.72 \pm 11.04$, $P<0.04)$ and QT dispersion (53.37 $\pm 313,76$ vs. $42.00 \pm 18.79$, $P<0.015)$ were longer in before operation than in after operation [Table 3]. The patient's echocardiographic values are shown in Table 4. It showed a marked reduction in RA pressure after surgery. The correlation analyses were demonstrated that there was a positive correlation between RVS'2-MPI 2 (after PEA) and P dispersion wave 1 (before PEA) [Table 5]. We have no data with PR dispersion associated with postsurgical atrial fibrillation. Overall intra- and inter-observer variability rates were similar.

\section{Discussion}

The main result of the present study in patients with CTEPH is the differentiation, among the ECG markers of arrhythmia risk, of those more strictly related to the QT and P dispersion and those better reflecting the malign arrhythmia and atrial fibrillation. To the best of our knowledge, this is the first study to characterize the ECG changes in CTEPH patients

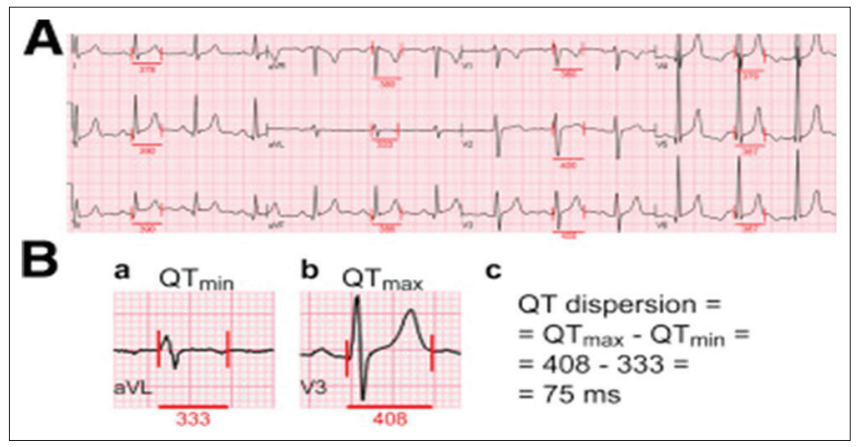

Figure 2: The QT dispersion is determined as the variation between the longest and shortest QT intervals in any origin in the standard 12-lead ECG 


\begin{tabular}{lc}
\hline Table 1: Patients' clinical characteristics at baseline \\
\hline & $\boldsymbol{n}(\%)$ \\
\hline Age & $57 \pm 26$ \\
Male sex $(n)$ & $39(62)$ \\
WHO class II/III/IV (\%) & $11 / 59 / 30$ \\
Previous deep venous thrombosis $(n)$ & $45(72)$ \\
Systemic hypertension & $18(30)$ \\
Diabetes mellitus & $4(6)$ \\
\hline
\end{tabular}

WHO: World Health Organization

\section{Table 2: Hemodynamic parameters of patients (before pulmonary endarterectomy)}

\begin{tabular}{lc}
\hline Hemodynamic & values-average \\
\hline $\mathrm{mPAP}(\mathrm{mmHg})$ & $48.7 \pm 14.9$ \\
$\mathrm{RAP}(\mathrm{mmHg})$ & $12.2 \pm 1.1$ \\
$\mathrm{CO}(1 / \mathrm{min})$ & $3.6 \pm 0.7$ \\
$\mathrm{CI}\left(1 / \mathrm{min} / \mathrm{m}^{2}\right)$ & $2.0 \pm 0.5$ \\
$\mathrm{PVR}(\mathrm{mmHg} \times \mathrm{min} / \mathrm{l})$ & $11.4 \pm 4.5$ \\
$\mathrm{SVR}(\mathrm{mmHg} \times \mathrm{min} / \mathrm{l})$ & $23.4 \pm 5.1$ \\
$\mathrm{PVR} / \mathrm{SVR}$ & $0.41 \pm 0.31$
\end{tabular}

Data are presented as mean \pm SD. mPAP: Mean pulmonary artery pressure, RAP: Right atrial pressure, CO: Cardiac output, CI: Cardiac index, PVR: Pulmonary vascular resistance, SVR: Systemic vascular resistance, SD: Standard deviation

undergoing PEA, and arrhythmia-related morbidity and mortality are associated with reduced risk after surgery. Such patients are an excellent clinical model to study the effects of treatment of pulmonary hypertension on ECG markers of arrhythmia: first of all because the consequences of surgery on CTEPH patients by far exceed the impact of pharmacological therapy in other forms of pulmonary hypertension, with the only possible exception of the effects of calcium antagonists in patients with PAH responsive to vasodilators. ${ }^{[15]}$ Second because in such patients there is apparent dissociation between the hemodynamic improvement, which is immediate after surgery, and the reverse remodeling of the right ventricle, which takes time, up to inadequate preservation of the right heart during the early postoperative period, with stunning being reversible over a few months, and tethering of the right ventricular wall due to adhesion between the heart and surrounding tissues. ${ }^{[15]}$ Table 3 showed a marked reduction in RA pressure after surgery; this itself reduces the atrial stretching, which is surrogate for future remodeling and arrhythmia development.

We observed that PR interval in ECG, P wave amplitude in DII decreased significantly soon after the intervention at 6 months. Data in the literature in different forms of pulmonary hypertension indicate that a high $P$ amplitude and a rightward-oriented QRS axis are linked to the presence of increased pulmonary pressures. ${ }^{[16-18]}$ The magnitude of the $P$ wave has also been previously reported to be of prognostic value in patients with PAH. ${ }^{[19]}$ Finally, it has been suggested that an elevated $\mathrm{P}$ amplitude in lead DII, in association with changes in QRS and T wave axis, could be an important

\begin{tabular}{|c|c|c|c|c|}
\hline & Mean $\pm S D$ & SEM & $\begin{array}{l}95 \% \mathrm{Cl} \text { of the } \\
\text { difference }\end{array}$ & $P$ \\
\hline HR1 - HR2 & $17.61 \pm-1.54$ & 3,16 & -8.01 & 0.628 \\
\hline PR1 - PR2 & $34.69 \pm 18.54$ & 6.23 & 5.82 & 0.006 \\
\hline QRS1 - QRS2 & $19.89 \pm 5.96$ & 3.57 & -1.32 & 0.105 \\
\hline Pwidth1 - Pwidth2 & $0.72 \pm 0.01$ & 0.13 & -0.24 & 0.902 \\
\hline PD21 - PD22 & $27.07 \pm 12.93$ & 5.02 & 2.63 & 0.016 \\
\hline PaVL1 - PaVL2 & $28.29 \pm 6.72$ & 5.25 & -4.03 & 0.211 \\
\hline PV51 - PV52 & $24.44 \pm 2.83$ & 4.46 & -6.29 & 0.531 \\
\hline QTD21 - QTD22 & $53.43 \pm 1.06$ & 9.92 & -19.25 & 0.915 \\
\hline QTaVL1 - QTaVL2 & $42.29 \pm-4.55$ & 7.85 & -20.64 & -0.579 \\
\hline QTV51 - QTV52 & $53.32 \pm 1.9$ & 9.73 & -18.01 & 0.847 \\
\hline Pdis1 - Pdis2 & $17.66 \pm 6.2$ & 3.27 & -0.51 & 0.04 \\
\hline QTdis1 - QTdis2 & $23.75 \pm 11.37$ & 4.41 & 2.34 & 0.015 \\
\hline
\end{tabular}

HR: Heart rate, PR: PR interval, QRS: QRS duration, PD2: P wave amplitüde in $\mathrm{D} 2$ derivation, PaVL: $\mathrm{P}$ wave amplitüde in aVL derivation, PV5: P wave amplitüde in V5 derivation, QTD2: QT duration in D2 derivation, QTaVL: QT duration in aVL derivation, QTV5: QT duration in V5 derivation, Pdis: P wave dispersion, QTdis: QT dispersion, SD: Standard deviation, SEM: Standard error of mean, CI: Confidence interval

Table 4: Patient's echocardiographic values at pulmonary endarterectomy before (1) and after (2)

\begin{tabular}{llccc}
\hline & $\boldsymbol{n}$ & Minimum & Maximum & Mean \pm SD \\
\hline EF1 & 62 & 50,00 & 80.00 & $64.73 \pm 7.06$ \\
EF2 & 62 & 50.00 & 80.00 & $64.50 \pm 6.94$ \\
TAPSE1 & 62 & 7.00 & 21.00 & $12.11 \pm 3.47$ \\
TAPSE2 & 62 & 7.00 & 27.00 & $14.30 \pm 3.96$ \\
RVS1 & 62 & 6.00 & 15.00 & $9.30 \pm 2.52$ \\
RVS2 & 62 & 7.00 & 13.00 & $10.24 \pm 1.94$ \\
MPI1 & 62 & 0.23 & 1.50 & $0.64 \pm 0.24$ \\
MPI2 & 62 & 0.24 & 0.85 & $0.49 \pm 0.16$ \\
TRGRA1 & 62 & 1.00 & 3.00 & $2 \pm 1$ \\
TRGRA2 & 62 & 0 & 2.00 & $1 \pm 1$ \\
SPAB1 & 62 & 32.00 & 127.00 & $83.07 \pm 27.50$ \\
SPAB2 & 62 & 15.00 & 67.00 & $32.34 \pm 13.39$ \\
RA1 & 62 & 10.00 & 41.00 & $25.42 \pm 8.68$ \\
RA2 & 62 & 11.00 & 33.00 & $17.72 \pm 5.50$ \\
RVED1 & 62 & 32.00 & 52.00 & $41.66 \pm 5.43$ \\
RVED2 & 62 & 28.00 & 41.00 & $34.92 \pm 3.98$ \\
\hline SD:Stan
\end{tabular}

SD: Standard deviation, EF: Ejection fraction, TAPSE: Tricuspit annular plane systolic excursion, RVS': Right ventricle systolic wave $(\mathrm{cm} / \mathrm{s})$, MPI: Myocardial Performance Index, TRGRA: Tricuspit regurgitation grade, sPAB: Systolic pulmonary artery pressure (mmHg), RA: Right atrium area $\left(\mathrm{cm}^{2}\right)$, RVED: Right ventricle end diastolic diameter $(\mathrm{cm})$

determinant of treatment response in PAH patients, implying that routine ECG evaluation could be a significant contribution to the assessment of therapy response in PAH patients. ${ }^{[20]}$ The present study is in agreement with such previous findings, additionally, showing that the reduction in $\mathrm{P}$ wave amplitude in lead DII over the $3^{\text {rd }}$ month.

The previous studies have shown that QT dispersion is an indicator for arrhythmia and CVD mortality ${ }^{[20]}$ 


\begin{tabular}{|c|c|c|c|c|}
\hline & QTdis1 & QTdis2 & Pdis1 & Pdis2 \\
\hline \multicolumn{5}{|l|}{ TAPSE1 } \\
\hline Correlation & -0.282 & $-0,286$ & -0.015 & -0.165 \\
\hline$P$ & 0.172 & 0.165 & 0.942 & 0.430 \\
\hline$n$ & 62 & 62 & 62 & 62 \\
\hline \multicolumn{5}{|l|}{ TAPSE2 } \\
\hline Correlation & -0.028 & -0.247 & 0.081 & 0.139 \\
\hline$P$ & 0.895 & 0.233 & 0.701 & 0.508 \\
\hline$n$ & 62 & 62 & 62 & 62 \\
\hline \multicolumn{5}{|l|}{ RVS1 } \\
\hline Correlation & -0.094 & -0.052 & -0.091 & 0.179 \\
\hline$P$ & 0.654 & 0.805 & 0.666 & 0.393 \\
\hline$n$ & 62 & 62 & 62 & 62 \\
\hline \multicolumn{5}{|l|}{ RVS2 } \\
\hline Correlation & 0.159 & -0.380 & 0.571 & 0.226 \\
\hline$P$ & 0.457 & 0.067 & 0.004 & 0.287 \\
\hline$n$ & 62 & 62 & 62 & 62 \\
\hline \multicolumn{5}{|l|}{ MPI1 } \\
\hline Correlation & -0.123 & -0.097 & 0.027 & -0.048 \\
\hline$P$ & 0.568 & 0.650 & 0.900 & 0.825 \\
\hline$n$ & 62 & 62 & 62 & 62 \\
\hline \multicolumn{5}{|l|}{ MPI2 } \\
\hline Correlation & -0.189 & -0.322 & 0.003 & -0.062 \\
\hline$P$ & 0.388 & 0.134 & 0.988 & 0.777 \\
\hline$n$ & 62 & 62 & 62 & 62 \\
\hline \multicolumn{5}{|l|}{ RA1 } \\
\hline Correlation & 0.006 & 0.184 & -0.178 & 0.280 \\
\hline$P$ & 0.977 & 0.379 & 0.394 & 0.175 \\
\hline$n$ & 62 & 62 & 62 & 62 \\
\hline \multicolumn{5}{|l|}{ RA2 } \\
\hline Correlation & -0.053 & 0.317 & -0.068 & 0.047 \\
\hline$P$ & 0.806 & 0.131 & 0.751 & 0.828 \\
\hline$n$ & 62 & 62 & 62 & 62 \\
\hline \multicolumn{5}{|l|}{ RVED1 } \\
\hline Correlation & 0.286 & -0.231 & -0.070 & 0.315 \\
\hline$P$ & 0.301 & 0.426 & 0.805 & 0.273 \\
\hline$n$ & 62 & 62 & 62 & 62 \\
\hline \multicolumn{5}{|l|}{ RVED2 } \\
\hline Correlation & 0.120 & 0.125 & 0.081 & 0.332 \\
\hline$P$ & 0.697 & 0.670 & 0.791 & 0.246 \\
\hline$n$ & 62 & 62 & 62 & 62 \\
\hline
\end{tabular}

TAPSE: Tricuspid annular plane systolic excursion, RV S': Right ventricle systolic wave (cm/s), MPI: Myocardial Perfusion Index, RA: Right atrium $\left(\mathrm{cm}^{2}\right)$, RVED: Right ventricle end-diastolic diameter $(\mathrm{cm})$, Pdis: P wave dispersion, QTdis: QT dispersion (1: Before operation, 2: After operation)

Tuncer et al. ${ }^{[21]}$ studied 25 patients with right ventricular hypertrophy without coexisting systemic hypertension, COPD, or PH who had emigrated from a high-altitude region to a low-altitude area 25 years previously and found that QT was significantly higher than in a healthy control group. Martin et al. ${ }^{[22]}$ found that QT was prolonged (defined as $\geq 0.45 \mathrm{~s}$ ) in two of 25 patients with right ventricular hypertrophy without other coexisting disorders but was not statistically significant in comparison with a healthy control group. Akgül et al. ${ }^{[23]}$ found that among patients with sickle cell disease, those with PH had significantly higher mean QTd than patients without PH. We discovered that QT dispersion changed a great deal at 6 months after surgery. Thereby, we believe that PEA may be diminished the risk of malign arrhythmia. QTc dispersion was found to be higher in patients without PEA than in a patient with PEA, and increased QT dispersion was not correlated with echocardiographic parameters in our study. This might be originated from our trial population is small.

Prolonged P-wave duration and increased P-wave dispersion are reported to carry an increased risk for atrial flutter or fibrillation. ${ }^{[24]}$ Many studies ${ }^{[25-27]}$ have shown that many diseases, such as PAH, bronchial asthma, diabetes mellitus, and acute rheumatic fever, in which the heart may be affected, exhibit a significantly longer P-wave duration. Large prospective clinical trials have shown that chronic atrial dilatation is an important and independent risk factor for the development of atrial fibrillation. ${ }^{[28]}$ In our study, there was a definite correlation between the MPI2-RVS2' (2: After PEA) and Pdis1 (1: Before PEA).The right ventricular systolic function may be increased as atrial stretch and preload decrease at the term of after operation.

We are aware that this study has some limitations. Foremost of these was a sample size smaller than that expected for a prospective cross-sectional study. The patients without PAH were determined by echocardiography alone, and right heart catheterization was not deemed to be ethical for these patients. This study should have an adequate number of patients in the mild, moderate, and severe groups to determine the correlation between the pulmonary artery pressure and dispersion durations.

\section{Conclusions}

Atrial and ventricular arrhythmia risks were found to be high in patients with PAH due to prolonged dispersion durations of P-wave, QT, and QTc. Further studies and multicentered studies are needed to enable an understanding of the underlying mechanisms and the diagnostic values of these electrophysiologic parameters. Physicians should pay close attention to possible atrial and ventricular arrhythmias during the clinical follow-up assessment and treatment of these patients.

\section{Financial support and sponsorship}

Nil.

\section{Conflicts of interest}

There are no conflicts of interest.

\section{RefEREnCES}

1. Lewczuk J, Ajlan AW, Piszko P, Jagas J, Mikulewicz M, Wrabec K, et al. Electrocardiographic signs of right ventricular overload in patients who underwent pulmonary embolism event(s). Are they useful in diagnosis of chronic thromboembolic pulmonary hypertension? J Electrocardiol 2004;37:219-25

2. Henkens IR, Gan CT, van Wolferen SA, Hew M, Boonstra A, Twisk JW, 
et al. ECG monitoring of treatment response in pulmonary arterial hypertension patients. Chest 2008;134:1250-7.

3. Al-Naamani K, Hijal T, Nguyen V, Andrew S, Nguyen T, Huynh T, et al. Predictive values of the electrocardiogram in diagnosing pulmonary hypertension. Int J Cardiol 2008;127:214-8.

4. Blyth KG, Kinsella J, Hakacova N, McLure LE, Siddiqui AM, Wagner GS, et al. Quantitative estimation of right ventricular hypertrophy using ECG criteria in patients with pulmonary hypertension: A comparison with cardiac MRI. Pulm Circ 2011;1:470-4.

5. Kopeć G, Tyrka A, Miszalski-Jamka T, Sobień M, Waligóra M, Brózda $\mathrm{M}$, et al. Electrocardiogram for the diagnosis of right ventricular hypertrophy and dilation in idiopathic pulmonary arterial hypertension. Circ J 2012;76:1744-9.

6. Tonelli AR, Baumgartner M, Alkukhun L, Minai OA, Dweik RA. Electrocardiography at diagnosis and close to the time of death in pulmonary arterial hypertension. Ann Noninvasive Electrocardiol 2014;19:258-65.

7. Mayer E, Jenkins D, Lindner J, D'Armini A, Kloek J, Meyns B, et al. Surgical management and outcome of patients with chronic thromboembolic pulmonary hypertension: Results from an international prospective registry. J Thorac Cardiovasc Surg 2011;141:702-10.

8. Madani MM, Auger WR, Pretorius V, Sakakibara N, Kerr KM, $\mathrm{Kim} \mathrm{NH}$, et al. Pulmonary endarterectomy: Recent changes in a single institution's experience of more than 2,700 patients. Ann Thorac Surg 2012;94:97-103.

9. D’Armini AM, Zanotti G, Ghio S, Magrini G, Pozzi M, Scelsi L, et al. Reverse right ventricular remodeling after pulmonary endarterectomy. J Thorac Cardiovasc Surg 2007;133:162-8.

10. Reesink HJ, Marcus JT, Tulevski II, Jamieson S, Kloek JJ, Vonk Noordegraaf A, et al. Reverse right ventricular remodeling after pulmonary endarterectomy in patients with chronic thromboembolic pulmonary hypertension: Utility of magnetic resonance imaging to demonstrate restoration of the right ventricle. J Thorac Cardiovasc Surg 2007;133:58-64.

11. Hii JT, Wyse DG, Gillis AM, Duff HJ, Solylo MA, Mitchell LB, et al. Precordial QT interval dispersion as a marker of torsade de pointes. Disparate effects of class ia antiarrhythmic drugs and amiodarone. Circulation 1992;86:1376-82.

12. Yunus A, Gillis AM, Duff HJ, Wyse DG, Mitchell LB. Increased precordial QTc dispersion predicts ventricular fibrillation during acute myocardial infarction. Am J Cardiol 1996;78:706-8.

13. Zareba W, Moss AJ, le Cessie S. Dispersion of ventricular repolarization and arrhythmic cardiac death in coronary artery disease. Am J Cardiol 1994; 74:550-3.

14. Martinez-Selles M, Baranchuk A, Elosua R, Bayés de Luna A, O'Neal WT, Kamel H, et al. Advanced interatrial block and ischemic stroke: The atherosclerosis risk in communities study. Neurology 2016;87:2499

15. Rich S, Brundage BH. High-dose calcium channel-blocking therapy for primary pulmonary hypertension: Evidence for long-term reduction in pulmonary arterial pressure and regression of right ventricular hypertrophy. Circulation 1987;76:135-41.

16. Henkens IR, Mouchaers KT, Vonk-Noordegraaf A, Boonstra A, Swenne CA, Maan AC, et al. Improved ECG detection of presence and severity of right ventricular pressure load validated with cardiac magnetic resonance imaging. Am J Physiol Heart Circ Physiol 2008;294:H2150-7.

17. Penaloza D, Arias-Stella J. The heart and pulmonary circulation at high altitudes: Healthy highlanders and chronic mountain sickness. Circulation 2007;115:1132-46.

18. Ahearn GS, Tapson VF, Rebeiz A, Greenfield JC Jr. Electrocardiography to define clinical status in primary pulmonary hypertension and pulmonary arterial hypertension secondary to collagen vascular disease. Chest 2002;122:524-7.

19. Bossone E, Paciocco G, Iarussi D, Agretto A, Iacono A, Gillespie BW, et al. The prognostic role of the ECG in primary pulmonary hypertension. Chest 2002;121:513-8.

20. Malik M, Batchvarov VN. Measurement, interpretation and clinical potential of QT dispersion. J Am Coll Cardiol 2000;36:1749-66.

21. Tuncer M, Gunes Y, Guntekin U, Aslan S, Gumrukcuoglu HA, Eryonucu B, et al. Association of increased QTc dispersion and right ventricular hypertrophy. Med Sci Monit 2008;14:CR102-105.

22. Martin AB, Garson A Jr., Perry JC. Prolonged QT interval in hypertrophic and dilated cardiomyopathy in children. Am Heart J 1994;127:64-70.

23. Akgül F, Seyfeli E, Melek I, Duman T, Seydaliyeva T, Gali E, et al. Increased QT dispersion in sickle cell disease: Effect of pulmonary hypertension. Acta Haematol 2007;118:1-6.

24. Dilaveris PE, Gialafos EJ, Sideris SK, Theopistou AM, Andrikopoulos GK, Kyriakidis M, et al. Simple electrocardiographic markers for the prediction of paroxysmal idiopathic atrial fibrillation. Am Heart J 1998;135:733-8.

25. Yücel O, Yildiz M, Altinkaynak S, Sayan A. P-wave dispersion and $\mathrm{P}$-wave duration in children with stable asthma bronchiale. Anadolu Kardiyol Derg 2009;9:118-22.

26. Köken R, Demir T, Sen TA, Kundak AA, Oztekin O, Alpay F, et al. The relationship between $\mathrm{P}$-wave dispersion and diastolic functions in diabetic children. Cardiol Young 2010;20:133-7.

27. Kocaoglu C, Sert A, Aypar E, Oran B, Odabas D, Arslan D, et al. P-wave dispersion in children with acute rheumatic fever. Pediatr Cardiol 2012;33:90-4

28. Psaty BM, Manolio TA, Kuller LH, Kronmal RA, Cushman M, Fried LP, et al. Incidence of and risk factors for atrial fibrillation in older adults. Circulation 1997;96:2455-61. 